\title{
Exploring the Impacts of Social Networking Sites on Academic Relations in the University
}

\author{
Patient Rambe \\ Office of International Academic Programmes, \\ University of the Free State, Bloemfontein, South Africa
}

\section{RambeP@ufs.ac.za \\ Executive Summary}

Social networking sites (SNS) affordances for persistent interaction, collective generation of knowledge, and formation of peer-based clusters for knowledge sharing render them useful for developing constructivist knowledge environments. However, notwithstanding their academic value, these environments are not necessarily insulated from the exercise of academic/ power. Despite a growing corpus of literature on SNS's capacity to enhance social capital formation, foster trust, and connect interactants in remote locations, there is a dearth of research on how SNS potentially leverages academic /power relations in university settings. Mindful of the unsubstantiated nexus between power relations, knowledge construction, and academic appropriation of SNS, unraveling the impact of SNS on lecturer-student and student-peer power relations in the university can illuminate the understanding of this academic connection/puzzle. This work employs Critical Theory of Technology (CTT) and virtual case study method to explore the influence of SNS use on power relations of lecturers, students, and their peers in a blended (Facebookenhanced) Information Technology course at a middle-sized South African university. The findings demonstrate that academic appropriation of SNS differentially empower academics and students at different times, and students employ various forms of sophisticated authorial language to territorialise power in their interactions with lecturers and peers. Academics and instructional designers are urged to examine different forms of language employed in lecturer-student and student-peer discourses to grasp student learning needs and to foster meaningful, knowledge-rich learning environments.

Keywords: Social networking sites, academic relations, critical theory of technology, differential power, meaningful learning

\section{Introduction}

This study investigates the impact of Social Networking Sites' (SNS) use on academic relations of lecturers and first year students on an Information Systems (IS) course at a middle-sized South

Material published as part of this publication, either on-line or in print, is copyrighted by the Informing Science Institute. Permission to make digital or paper copy of part or all of these works for personal or classroom use is granted without fee provided that the copies are not made or distributed for profit or commercial advantage AND that copies 1) bear this notice in full and 2) give the full citation on the first page. It is permissible to abstract these works so long as credit is given. To copy in all other cases or to republish or to post on a server or to redistribute to lists requires specific permission and payment of a fee. Contact Publisher@InformingScience.org to request redistribution permission.
African university. Social networking sites are web-based services that allow individuals to (1) construct a public or semi-public profile within a bounded system, (2) articulate a list of other users with whom they share a connection, and (3) view and traverse their list of connections and those made by others within the system (Boyd \& Ellison 2007). In spite of the exponential uptake of SNS by university entrants in South Africa 
and the world over as spaces for the micro management of their lives and sharing of educational material, little is known about the impact of these sites on lecturer-student academic relations. Cummins (1997, p. 423) suggests that academic relations involve "coercive and collaborative relations of power that operate at both the broader societal level (macrointeractions) ${ }^{1}$ and the interpersonal level (microinteractions)." Because of the interpersonal nature of social networked interaction, our work essentially targets micro relations of power of academics and students in a Facebook environment. Micro interactions ${ }^{2}$ are "an interpersonal or an interactional space within which the acquisition of knowledge and formation of identity is negotiated. Power is created and shared within this interpersonal space where minds and identities meet" (Cummins, 1997, p. 425). Given their transactional nature and their capacity to activate higher psychological functioning and identity formation, Facebook-enhanced micro interactions are more insightful for unpacking academic/power relations and learning in university learning environments than macro interactions, hence our deliberate focus on them.

The deep immersion of youths in SNS in the university has spurred substantial academic interest in these sites, particularly how they activate social capital, enable the exchange of friendship networks and knowledge, and invoke privacy considerations (Bosch, 2009; Ellison, Steinfield, \& Lampe, 2007; Flynn, 2008; Gross \& Acquisti, 2005; Lampe, Ellison, \& Steinfield, 2006; Lenhart \& Madden, 2007; Peluchette \& Karl 2008). In spite of this emerging body of academic literature that acknowledges SNS use in academia, there is limited research on the impacts of such use on social power relations. Yet, the purpose of SNS is building relationships, moulding identities and sharing and, hence, "networking," which render them useful for unraveling social power relations in academia. What seems problematic, therefore, is unpacking what influence SNS use has on power relationships and whether they enable or disrupt lecturer-student and student peer relations. The role of relationships and academic networking in knowledge production makes the unpacking of power dynamics/academic relations useful for grasping these processes of knowledge production.

Bishop-Russell, Dubord, Hansen, \& Webster (2006) reiterate that Facebook's online community meets the requirements set forth by Chickering \& Reisser (1993) for an environment that promotes student development by providing regular interaction between students and opportunities for collaboration with people from diverse backgrounds and that serves as a social reference group. These affordances for collaborative networking and persistent interactions present Facebook as a vantage point for unraveling lecturer-student power relations, if academics support was rendered via this site.

The shifting notions of what constitutes an academic community further necessitates researchers to transcend face-to-face interaction to examine online networks with a view to grasp academic relations as more students develop clusters on SNS for the exchange of learning resources, relationships and support. As such, Riva \& Galimberti (1998) contend that, where residence halls, student unions and classrooms once thrived as the centres of collegiate community, virtual reality has diminished the necessity of these geographic locations for community formation. Identifying with Riva \& Galimberti, I suggest that Facebook provides a democratic and "user friendly" environment for student engagement in communities of practice in ways that traditional learning spaces like learning management systems least afford to do. Such environments present opportu-

\footnotetext{
${ }^{1}$ Macrointeractions and microinteractions are presented in Cummins' (1997) work unhyphenated. We present them in this work as macro interactions and micro interactions.

${ }^{2}$ We will refer to micro interactions in learning settings as micro level academic relations and those at the macro level as macro level academic relations.
} 
nities not only for transformative learning but more importantly, the contestation of relational power and influence, the essential catalysts for productive knowledge construction.

\section{Research Questions}

Acknowledging social networked interaction as a discursive practice through which knowledge construction obtains and power relations unfold, we pose the following research questions:

1. What forms of language do academics and students use to exercise power on each other in social networked (SN) interaction?

2. a) How does SN interaction (via textual messages) potentially entrench/disrupt power relations?

b). What are the subsequent effects of these disruptions/entrenchments of power on lecturer-student and student-peer engagements?

3. What insights does the academic support for students via SNS provide on the challenges of hierarchical academic relations?

\section{Literature Review}

With over 98 percent of students at a world class South African university having cell phones and anecdotal evidence showing that texting is their modulus operand of communication (Centre for Education Technology, 2009), it can be argued that students have augmented SNS interaction via computers with exchanging learning resources on SNS-enhanced phones. The academic relations built on these sites remain under-researched in academia. Many studies into SNS have concentrated on connectivity, relation building, and privacy considerations but have not given preeminence to the exercise of social power. This understanding is discussed in greater depth in studies articulated below.

Peluchette and Karl's (2008) study of 433 undergraduate students at a Midwestern university in the United States' use of and attitudes towards SNS reports their tendency to be naive about the potentially negative consequences of access and use of their information by other people. Their findings are insightful for University career and job placement centres that need to advise students on the possible consequences of their website postings during freshman orientations through student codes of conduct and information technology policies. While the study invokes privacy and self-image implications of postings, it does little to illuminate understanding of the impact of these sites on lecturer-student relations in learning context.

Hewitt and Forte (2006) researched the Facebook interactions of two large classes (comprising 176 students) in a middle-sized public research university to unpack how their online contact influences their perceptions of faculty staff. Mixed results were reported, with two thirds of the students affirming their Facebook interactions with faculty staff as presenting alternate communication channels and affording their acquaintance with professors. To the contrary, a third of the students felt that faculty staff had no justification for being on Facebook, and others cited privacy considerations and identity management as key concerns in student-faculty relations. Although their study cast light on the challenges of maintaining hierarchical relations in Facebook, it was not foregrounded in the exercise of social power in developing world contexts. More importantly, Facebook use was a student self-initiative rather than a faculty requirement, as was the case in this current study.

Ellison, Steinfield, and Lampe's (2007) study examined the relationship between university students' use of Facebook and the formation of social capital and found a strong correlation between these variables. They argued that the strong linkage between Facebook use and high school con- 
nections suggests how online social networks afforded the persistence of relations as people migrate from one offline community to another. They elaborated that the same obtained when these students graduated from university and maintained contacts as alumni whose connections would pay dividends in terms of jobs, internships, and other opportunities. While Ellison, Steinfield, and Lampe's study focused on student-peer relations and the maintenance of social capital, lecturerstudent interaction was not the focus of their study and Facebook engagement was neither lecturer driven nor part of the course requirements. The current study seeks to examine both lecturerstudent and student-peer interaction in a blended course where their department expected students to formally consult with academics via Facebook.

A review of SNS use in pharmacy education conducted by Cain (2008) exposed both the potential and challenges for academics and students when using these sites. It reports that SNS afford students connectivity with users with similar interests, allow them to foster and maintain relationships with friends, and bestow a sense of collegiality on campus. The downsides of SNS use included exposing student online personas to public scrutiny and risking their physical safety by revealing excessive personal information (Cain, 2008). Similar studies that emphasised student/youth security and privacy on SNS and potentially tainted academic profiles related to Webbased sites abound (Bosch, 2008; Chigona \& Chigona, 2008; Kolek \& Saunders, 2008; Lipkin, 2006; Read, 2006). These studies are, however, not anchored in how SNS mediates relations of power in university academic settings. The remarkable interest in academic relations on SNS is predicated on the understanding that these relations are potentially interfaced with academic identity formation and the building of collaborative knowledge through student clusters.

\section{Theoretical Framework}

To unravel how Facebook interaction potentially entrenches/disrupts power relations and its implications on lecturer-student and student-peer relations, the study employs Critical Theory of Technology (CTT) as a theoretical lens. To advance CTT, Feenberg (1999) first critiques three other views of technology. The first is an instrumental view of technology that projects technology as a value-free artifact that humans deploy to fulfill their pre-determined goals (human controlled). This view conceives "technology [as] merely as an instrument of progress and it appears as value-free; in other words it is deemed 'neutral'" (Vandeleur, 2010, p. 21). Heidegger (1977) warns that a neutral and instrumental perspective on technology triggers the 'enframing' of humans by technology as it (technology) is a form of technical and social control. The construction of Facebook as a value free technology can result in unsophisticated students with limited ICT literacy conceiving Facebook as an educational tool for educator transmission of content. Failure to critically question the fundamental logic and cultural values behind a technology result in suboptimal engagement with and using the technology. Corporate profiteering from user generated content, procrastination, fatigue, and information overload are practical manifestations of the hidden, exploitative side of Facebook. These persist if students are not apprised of the negative values that emerge from unproductive use of Facebook.

Feenberg (1999)'s CTT also critiques the determinist view of technology that locates technology as a neutral manifestation of social progress that humans are inevitably coerced to participate in (neutral, autonomous view of technology). Dusek (2006) points out that "technological determinism is the claim that technology causes or determines the structure of the rest of society and culture" (p. 84). This implies the neutral, autonomous existence of technology, which is based on its operational logic and that societal innovations are a function of technical progress. Feenberg (2005) notes that in determinist and instrumentalist accounts of technology, efficiency serves as the unique principle of selection between successful and failed technical initiatives and, on these terms, technology appears to borrow the virtues generally attributed to scientific rationality. Feenberg (1999) critiques this view for its erosion of human control and lack of recognition of 
human agency in their use of technology. In a Facebook learning environment, it is logical to argue that students operate within the technical specifications and affordances of this technology. Yet this view ignores the reality that open, critical application of Facebook can give rise to novel, unanticipated uses of Facebook, hence the human-controlled view of technology.

Although Feenberg (1999) embraces the substantive view of technology that recognises technologies as embodying real, substantive values, he critiques it as essentialist to the extent that it conceives technologies as inevitably oriented towards values of efficiency and control (cited in Gratham, 2009). In the same vein, constructing Facebook this way precludes the questioning of the hidden assumptions and values about power, social struggle, and critical engagement that underlie its (Facebook) design. Working from this logic, Feenberg $(1999,2003)$ then projects the value of CTT.

CTT conceives of technology as human controlled and value laden (Feenberg, 2003). Human controlled implies that humans can appropriate technology to advance certain purposes (for example, the exercise of power and influence, social networking, or informal learning) and to activate new, unanticipated uses of technological applications/tools. Therefore, academics and students, as technological agents, can ideologically deploy text-based interactions to direct their referent persons' (lecturers peers, extended academic community) actions and mental dispositions towards their intended academic interests, to exert their academic authority, and to communicate their learning needs respectively. For IT students, effective appropriation of Facebook can involve using Facebook as an information repository, using discussion group threads to develop a loose theme dependent 'database,' using Facebook as a file sharing and storage platform (similar to Google Docs), and adopting Facebook networks to foster academic research relationships. For academics, Facebook can render prognosis for identifying content areas students struggle with and diagnostic tools (e.g., quizzes) for assessing student performance on general theory and IT knowledge. Facebook can also provide a mediational space for navigating and negotiating complex academic relationships between lecturers and students. As such, in CTT, power circulates through technology's (the medium) affordances and constraints and manifests through the actions and reactions of academics and learners (knowledge agents) in communicative events and interactions.

Feenberg \& Barney (2004) submit that all technological artifacts exhibit interpretive flexibility, that is, different participants in the design process differently understand them. At the user interface level where academic relations unfold, interpretive flexibility in SNS entails the psychological advantages and opportunities presented to academic agents (academics and students) to entrench or subvert hierarchical power relations (lecturer-student and intelligent student-peer) often explicit in classrooms. Brey (2008) succinctly notes that technology can be appropriated to establish or maintain asymmetrical power relations through empowering the power holder while disempowering the power endurer triggering differential empowerment. He elaborates that this implies that technical artifacts may also differently empower agents by making a different fit with their interests and attributes. Power agents in an academic relationship may seek to control the psychological disposition of the other. Interpretive flexibility may imply that the computermediated nature and less rigid technical controls in SNS architecture potentially neutralise offline hierarchical power through making it less explicit and equalising opportunities for student innovative use of SNS collaborative tools. More so, the openness of technological devices to varied interpretations enable users to draw diverse conclusions about its nature and purpose, independent of the intentions of computer designers or deterministic technical constraints (Brey, 2008)). Mindful of SNS as collaborative "student-controlled spaces" (Rambe, 2009), one could conceive of them as spaces for demonstrating self-initiative, contesting or evening out the unfavourable balance of power between themselves and academics built in instructivist teaching modes. 
Heidegger (1977) warns against the uncritical acceptance of technology as neutral and merely instrumental and suggests that this naive celebration of technology leads to being chained and imprisoned by technology. He cautions that a technicist approach to technology fails to liberate humans from technological domination. Technological determinism fosters unbalanced academic relations as it forecloses the possibilities of using technology in innovative ways to promote meaningful learning while diminishing the negative consequences of technology on human agency. The construction of technology as value laden denotes that technological artifacts emerge from the political and ideological contestations that occasion systems designers and other participants in technological design process. At the human-computer interaction level, technology then imposes these values, motives and interests on users. As Feenberg and Barney (2004) note:

In the early stages, humans imagine the possible use of technology but as the technology is stabilized, its design tends to dictate users' behaviour more successfully and agency tends to recede into the background, at least until new demands emerge to challenge the established design. (p. 14)

I infer a dual, dynamic, and reciprocal relationship between human action and technology involving academic agents experimenting with different possible applications of technology during their induction phases (emancipatory phase) and the technology's ideologies subordinating users' motives and intentions in later phases of technological deployment (technological determinism phase). While I concur with Feenberg and Barney (2004) that the human-technology relationship is reciprocal, I doubt the applicability of the linear approach implied in their theorisation. Suffice it to suggest that operationalising CTT at the user interface level could involve an interrogation of how academic agents (lecturers or academically gifted students) gainfully use technological affordances and language to exercise their authority, agency, and influence on students or academically challenged peers respectively.

\section{Methodology}

This study adopted Critical ethnography as a methodological approach. Simon and Dippo (1986) suggest that Critical ethnographic work is both pedagogical and political because it conceptualises our society as inequitably structured and dominated by a hegemonic culture that suppresses an understanding of how society functions the way it does and what must be done for it to change. Drawing on their view of transcending the dominant culture and critical questioning of the status quo, I used Facebook interaction to explore how interactants in a conceivably asymmetrical relationship subverted as well as entrenched their social power and exercised/resisted the agency of one another. More importantly, I examined the different types of text-based language discourses that academic agents marshaled on Facebook to activate, reinforce, and resist the psychological control of others.

\section{Case Study}

The study examined three first year Information Systems (IS) classes that were required by their department to use Facebook as an academic consultation and networking space with academics and peers. Because of huge classes that constrained one-on-one lecturer-student academic consultations, students were encouraged to sign on Facebook and to join the IS Facebook group to facilitate need-based academic support from the lecturer and knowledgeable peers. One regular IS lecturer, designated as an online administrator, addressed student queries and questions on theory, practicals, and course administration issues while the other lecturer with an online presence marginally supported students on general course administration.

These undergraduate students attended different class sessions but were taught the same content by the same lecturers. Out of the 450 undergraduate students who constituted these classes, 165 
students participated in this study over a period of a year. The students had three interactional spaces on Facebook for consulting with the online administrator and peers, namely, the administrator's Facebook inbox, special discursive feature (discussion board), and the Facebook wall. Students posted 414 posts on Facebook, and those who did not participate were excluded from this study. These participants posted 154 wall posts, 121 discussion board posts, and 139 posts to the administrator's inbox. The study was interested in the discursive language employed by the lecturers and students on Facebook, the hidden assumptions about power embodied in their textual messages, and implications for agency of the structural and syntactical nature of phrases adopted.

\section{Analysis of power manifested in discourse}

Fairclough (1989) suggests that power manifests behind discourse through efforts to standardise language forms or impose specific language formats and this limits who speaks, who is heard, and about what. Fairclough's $(1989,1995)$ Critical Discourse Analysis (CDA) provides a useful analytical framework for unpacking relational control expressed through language in several ways:

1) It (Fairclough's CDA) provides an analytical lens for exploring often opaque relationships of causality and determination between discursive practices, events, and texts (Fairclough, 1995). This means it renders an interpretive scheme for abstracting micro level properties of communication (text structure) from the macro aspects (social practices and vice versa). Therefore, by interrogating students' Facebook postings (text), some inferences can be made about social controls, hidden power structures, and other constraints the broader academic environment (social structure) imposes on the interaction. Similarly, an examination of discursive practices (social structure) can inform the understanding of the fundamental meaning and constitution of text and, hence, the dual, reciprocal relationship of structure and text.

2) Wider social and cultural structures, relations, and processes can be used to investigate how discursive practices, events, and texts arise out of and are ideologically shaped by relations of power and struggles over power (Fairclough, 1995). The nexus between overt (and hidden) power, ideology, and text descriptions on the one hand dovetails with the affordances and constraints technology impose on the production of agency in academic spaces on the other. On Facebook, therefore, the hierarchy of student textual constructions, events that trigger them, discursive and social practices (in the academic environment), and the interplay of social power at all these levels mirror the dual reciprocal relationship between structure and agency in technology mediated interaction (Facebook). Structure manifests in technical specifications of Facebook, for instance, a requirement for a Facebook profile, which bring para-social relations that may constraint the freedom social agents enjoy in online communication and limits on the number of characters they can enter on Facebook (240 characters) per given time. Agency manifests in different communication channels rendered on Facebook (private and public communication), number of friends permitted, number of groups agents may join, and the different levels of privacy afforded on agents' profiles.

3) Fairclough's (1995) CDA allows us to explore how the opacity of these relationships between discourse and society is itself a factor in securing power (p. 132-133). In a Facebook environment the relationship between academic authority, IT knowledge production, and articulation of IT discourses render a viable proxy for unraveling texts as micro level incarnations of power in society. Having provided a justification for the use of Fairclough's CDA, the study proceeds to demonstrate the application of CDA in this work. 
Consistent with Fairclough's (1989) three-dimensional hierarchy of description, interpretation, and explanation, we examined power relations in Facebook discourses and language structures. I also employed additional analytical tools Fairclough uses in relation to language, like use of modality, language that carries assumptions about power (questions, exclamation marks), language with expressive, relational and ideational significance, grammatical properties with authorial claims and syntactical and phonetic structures of text.

Table 1. Analysis of interactional power using Fairclough's (1989) CDA

(All the names adopted in this work are not authentic names of these participants.

This is to protect the identity of research subjects.)

\begin{tabular}{|c|c|c|c|}
\hline Text (posts) & Description & Interpretation & Explanation \\
\hline $\begin{array}{l}\text { Mandla: hey Theron } \\
\text { I'm Mandla from one } \\
\text { of your classes. }\end{array}$ & $\begin{array}{l}\text { 'Hey' is informal. } \\
\text { Lecturer is } \\
\text { addressed by first } \\
\text { name instead of } \\
\text { the title. }\end{array}$ & $\begin{array}{l}\text { Use of informal } \\
\text { language is expressive } \\
\text { and relational. It } \\
\text { portrays the student } \\
\text { attempt to level rela- } \\
\text { tions of power. }\end{array}$ & $\begin{array}{l}\text { Lecturer-student } \\
\text { online relations are } \\
\text { purportedly symmet- } \\
\text { rical. } \\
\text { Facebook allows } \\
\text { students to negotiate } \\
\text { power through } \\
\text { addressivity. }\end{array}$ \\
\hline $\begin{array}{l}\text { I asked you for that } \\
\text { journal article re- } \\
\text { member? So please } \\
\text { make it a point that } \\
\text { you bring it on your } \\
\text { flash drive tomorrow } \\
\text { at the tutorial, thank } \\
\text { you!!! (IP 128) }\end{array}$ & $\begin{array}{l}\text { 'Make it a point' } \\
\text { resonates with the } \\
\text { student interest } \\
\text { to impose control. } \\
\text { Use of exclamation } \\
\text { marks serves a author- } \\
\quad \text { ial function }\end{array}$ & $\begin{array}{l}\text { Student manipulates } \\
\text { lecturer's promise into } \\
\text { an obligation. He } \\
\text { imposes a directive } \\
\text { the lecturer has to } \\
\text { honour. } \\
\text { The marks express } \\
\text { urgency on the com- } \\
\text { municant's part. }\end{array}$ & $\begin{array}{l}\text { In educational } \\
\text { contexts, lecturer- } \\
\text { student relations } \\
\text { are expected to be } \\
\text { hierarchical. } \\
\text { The informal nature of } \\
\text { Facebook gives the } \\
\text { student the leeway to } \\
\text { subvert these power } \\
\text { relations. }\end{array}$ \\
\hline $\begin{array}{l}\text { Administrator's } \\
\text { response } \\
\text { Hi, Mandla you must } \\
\text { learn to write politely } \\
\text { otherwise you will } \\
\text { not get what you want } \\
\text { in future. } \\
\text { Theron (IP 129) }\end{array}$ & $\begin{array}{l}\text { must' is a } \\
\text { modal auxiliary. } \\
\text { It is expressive of } \\
\text { relational authority } \\
\text { of the lecturer. } \\
\text { 'will not' is definitive }\end{array}$ & $\begin{array}{l}\text { The implicit rule is } \\
\text { the use of polite } \\
\text { language when } \\
\text { inquiring from a } \\
\text { superior }\end{array}$ & $\begin{array}{l}\text { The African culture } \\
\text { imposes expectations } \\
\text { that the young should } \\
\text { treat the old with } \\
\text { dignity and respect. } \\
\text { This African } \\
\text { academic transfers } \\
\text { this custom into } \\
\text { academia by } \\
\text { expecting the same } \\
\text { from her students }\end{array}$ \\
\hline
\end{tabular}

\section{Findings on Facebook Posting}

The findings of the study will be presented in this way: First, Facebook interactions involving academics' appropriation of authoritative language and student responses to these forms of social 
control will be discussed. This is followed by a presentation of scenarios where students were at liberty to extend their influence and express their agency and, subsequently, instantiations of student satiric critique of faculty's administrative processes and, lastly, the performance of gender in interactions.

\section{Modality and lecturer's dispositional power}

For the three interactional spaces, similar discursive practices were applied that embodied assumptions about lecturer authority though there were some cases where the students disrupted and contested this authority. Since the Facebook postings on the interactional spaces (Facebook wall, discussion forums, inbox messages) were generally similar, it was considered convenient and expedient (in light of constraints of space) to examine them (postings) thematically rather than analysing them based on the spaces from which they were extracted. Fairclough's (1989) three tier hierarchy is employed for the analysis of postings.

At text property level, the lecturer's ${ }^{3}$ appropriation of auxiliary modes in Facebook discourses signifies her position of control in hierarchical relations with students. At the level of interpretation, modal auxiliaries denote the knowledge expert's deliberate calculation to regulate and control students' psychological disposition and behavioural actions during online consultative sessions. Modes like "must," "should," "will," and "need to/have to" impose an obligation for subservient party's compliance and privileges the speaker thus affirming her designated position of unfettered authority. The explanation for applying this language genre is that, in traditional didactic instruction, lecturers have a legitimate claim to authority in their academic relationship with students by virtue of their professional training and as knowledge experts. Her exercise of dispositional authority and control is unquestionable in light of this ground rule. An example of the application of these modes is the lecturer's response to the student request highlighted below:

Hi Theron I have been assigned topic 12.5 for the IS literature review. I have tried to research it at the library and on the internet but cannot find any material. Is it possible to change topics? [...]. Thanks (Inbox Post (IP 33)).

The student inquires from the lecturer the possibility of changing the literature review topic he was assigned as there is dearth of literature on it. The request embodies the subordination of the inquirer before an incumbent higher authority. Consistent with Foucault's (2003) conception of power as a technique that subjugates individuals, making the inquiry positions the student as a subject whose subservient identity is tied to the lecturer's stock of self-knowledge and discretion. In her response, the lecturer notes that:

not possible. unfortunately you will have to contact your lecturer who taught that chapter for further assistance. Theron (IP 35)

The objection and the modal auxiliary "will have" encodes an air of authority of the lecturer over student. The subtle form of control unfolds in a SNS academic context that affords the expert a privileged position to direct and support students with academic queries. It resonates with the lecturer's authorial position to give expert guidance and a definitive plan of action the student should take. The technology (Facebook) is the medium through which ideological interests to regulate the intentions and psychological behaviour of the student is effected.

\footnotetext{
${ }^{3}$ The lecturer referred to is the one who assumed the online administrator's role.
} 


\section{Appropriation of imperatives to wrestle social power}

Students also inscribed imperative statements meant to galvanise and consolidate power in this perceivably "student controlled" space. A typical case of this endeavour is the lecturer-student engagement cited below:

hey Theron I'm Mandla from one of your classes. I asked you for that journal article remember?? So please make it a point that you bring it on your flash drive tomorrow at the tutorial, thank you!!! (IP 128).

The student demands the lecturer to honour her promise of bringing him an article in her next tutorial. He employs an imperative phrase "make it a point that" as a way of subverting a conceivably hierarchical relationship and territorialising control. As Foucault (2003) reiterates, power relations are exercised through the production and exchange of signs, and these signs are not separated from goal-directed activities that permit the exercise of power such as training techniques, process of domination, the means by which obedience is obtained. If signs are interpreted as human intentions, then the student's attempt to secure the lecturer's obedience in pursuit of his ideological interest to control her actions/intentions constitutes a power contestation process. In response to this overt intention to regulate behaviour, the lecturer wittily retorted:

Hi Mandla, you must learn to write politely otherwise you will not get what you want in future. Theron (IP 129).

The lecturer's lash at the subversion of her authority is carried in the reprimand: "you must learn $[\ldots]$ otherwise you will not [...]" Her chide reproach vividly reminds the student where the dispositional power lies and normalises the configuration of power by reclaiming her control. Language in technology-mediated interaction works as a technique through which power is contested and reclaimed for individual or collective ends.

\section{Authorial claims}

Claims to authority are statements that convey some assumptions on the dispositional power of the speaker over the referent person. They afford the power agent the legal right and express legitimacy to impose an obligation on the power endurer to get a prescribed course of action adopted consistent with the agent's motives and intentions. Authorial claims pervaded discussion board and wall interactions. The student statement below expresses her confusion caused by a lack of understanding of the IS course:

yes I am so lost in IS I'm not enjoying it at all because I do not understand what is happening. (DBP (discussion board post) 46)

Administrator's response:

Be specific Naidoo... it's the only way I can help you. WHAT are you lost in? which chapter, which concept, etc...it makes it easier for me to help. Theron (DBP 49).

The phrase 'be specific' demonstrates the lecturer's ideological position of influence through her definition of the discourse structure (by critical questioning instead of giving an ambiguous answer) as a condition of her assistance. The subsequent statement 'it's the only way' has expressive and relational significance. Expressively, it frames the discourse as unsustainable if the student retains the ambiguous stance she adopts. Relationally, it signals potentially negative sanctions that may be imposed by the lecturer if these conditions are unmet, for example, withdrawal of assistance or rebuff. The social context of SNS-mediated discourse locates the lecturer in an instructional and advisory capacity that increases the memory of the cognitively challenged student. The technology provides different textual resources and interactional context with authorial 
implications-question marks, directive language and infinite expressions to demonstrate that the speaker could have said more, for example, ellipses.

In another communicative event between the lecturer and a student, the learner is unclear about the topic to review. She inquires about the correct topic and the lecturer responds:

According to Vula ${ }^{4}$, you are up for chapter 9.7. stick to that (DBP 105).

The phrase 'stick to that' has expressive significance as it carries the authoritative power of the author over the recipient of the text. Van Dijk (2001) notes that if controlling discourse is a first major form of power, controlling people's minds is the other fundamental way to reproduce dominance and hegemony. The lecturer's expressive claims to authority are naturally legitimised through student compliance with the expressive directives she gave.

\section{Possibilities for personal agency}

Interactive power relations in social networked environments are not exclusively about authority ridden modalities like "must," or "should" but rather entail mutually beneficial collaborative engagements as well. Productive forms of power provide room for agency. To this effect, the lecturer also employed modalities that render greater discretion for students through harnessing permissive language like "may," "can," and "could." In the extract below the student poses a procedural question to generate understanding in task execution:

hey Theron. the form that we are doing is it for the customers? If so then should we exclude other things like dispatch details. (IP 40).

The lecturer serves a possibility mode that renders the student greater leverage for independent action:

you can choose to do any form [a]ny table or query, it entirely up to you. Theron (IP 41)

This posting attests that exercising effective authority on SN interactions is not entirely about restraining online behaviour but can be emancipatory as well. Interactive power, therefore, constitutes a productive force that directs actions to accomplish certain learning goals apart from being a seductive, restraining force and resource in oligarchic hands. As Foucault (1981) aptly writes, "Power is not something that is acquired, seized or shared, something one holds or allows to slip away ..." (p. 94). Therefore, possibility modal verbs like "may" and "can" provide frames for conditioned agency in task accomplishment.

Grammatical features can embody negative or positive framing of agency in sentence construction, syntaxes, and verbs used. A lecturer's response to a student who implores her concerning tutorials demonstrates the positive framing of agency:

$\mathrm{Hi}$, I don't feel learn enough in tutorials, cause being only one tutor, not really able to answer questions...could we have another day of extra tutorials...(DBP 39)

The student is discontented with tutorials because the tutor is unable to address the numerous queries students often raise hence the request for extra tutorials. In her response, the lecturer harnesses agentive language to promise redress:

Hi Jacqueline. It would be difficult to arrange for another class but [I] will see what we can come up with [...].Theron (DBP 40).

\footnotetext{
${ }^{4}$ Vula is this South African university's instance of Sakai based learning management system.
} 
The phrase 'will see what we can come up with' resonates with the lecturer's agency in decision making in support of students. The lecturer had wider scope for intervention in response to this query: to increase the number of tutors, raise the number of consultation sessions per week, or extending the consultation times.

\section{Satirical critique of administrative practices}

The dynamism and computer-mediated nature of Facebook afforded students the opportunity to use political satire in expressing their displeasure with department lecturers' practices. Students sarcastically grumbled about the department's requirement for compulsory opening of Facebook accounts and joining of the department Facebook group. Students feared the possibility of academic access to their private personal lives via Facebook. These subtle critiques are discussed each in turn:

I really wonder is this what they expect from the elite of African students [...] (WP 149).

The student is sceptical about the academic significance of Facebook use by what he conceived as African elites enrolled at an elite university. This rhetoric statement conveys disgruntlement and implicit search for redress. Where relations are assumed to be hierarchical, the strategic use of rhetoric language in Facebook to express displeasure becomes a more effective way of lodging complaints than direct confrontation. This style is also emulated by two other students:

Ok I have joined now what? do i get a gold star? (WP 141).

Wow, was this really necessary? (WP 130).

These ironic statements constitute smart, euphemistic ways of dealing with sensitive controversial issues without meddling with academic authorities' positioning. They may succeed in relaying the message of discontent if academic authorities take these complaints seriously. Another student who seems unapologetic adopts a more scathing critique:

here it seems that the University of X (name of department given)-X and Y (name of technology related classes given) students need more than just a helping hand I think someone should help them-Vula!!!(open) all their closed doors. With regards to (their course) that is VALA (closed) (WP 139).

The student seems annoyed by the perceived inaccessibility of lecturers in this department in spite of students' urgent need for assistance. The adoption of the vernacular terms like "Vula" (open) and "Vala" (close) veneers the critique with euphemism while the appropriation of capitals for both terms betrays this facade. As such, though the statement is cast in an ironic mode, it ends up more apparent.

\section{The 'exhibitionist' attitude of male posts}

Male students posted messages on the department Facebook wall that were expressively chauvinist. Once posted, wall and discussion board posts become publicly available to all Facebook group members. This publicity potentially boosted the self-esteem of some male students who craved public attention among peers and females. They could have nourished their ego and pride by exhibiting their macho to watchful invisible audiences. Some of these 'exhibitionist' statements displayed on the wall are:

[Name of residence given] young men are in this room again, again...You guys probably know the rest by now! [Name of residence] Yeah!!!!!!! (WP 134)

This wall posting sounds like a proclamation of a social activity that male students are renowned for hence, the "You probably know the rest by now" statement. The utterances serve to glorify this 
"gentleman's club" that the student casts in limelight. The projection of one's affiliation resonates with the self-pride embodied in the statements below:

\section{HAHAHA guys don't you think this a lil random! i think this is supposed to make IT coolers ;) (WP 135).}

The conversational nature of this posting, the laughter, a direct statement that hints to a watching audience and an emoticon ${ }^{5}$ signify a subtle commitment by this lad to be heard. The exhibitionist attitude of some young men is apparent in these spaces where virtual bodies are publicly paraded. It can thus be assumed that the statement is uttered with the boy's audience in mind.

\section{The use of informal language}

Language structures are also vantage points from which to grasp the different ways collaborative discourses shape academic relations. In a bid to create accessibility to students in a quasi-formal space, the lecturer diversifies her use of language. These include informal language and other language structures that create a sense of welcoming aura to students. The following are extracts of the administrator's conversations with students and announcements:

The diagrams are not compulsory ...it depends on what you have gathered on your work. However a picture explains better sometimes [...] Cheers (DBP 53).

The appropriation of informal words like "cheers" (for good bye) by the administrator is meant to bridge the gulf between the students and her in terms of academic status and to nurture a cordial working relationship. This communicative genre ensures that she identifies more with the students making them predisposed to asking her some questions. The same can be said of the opening phrase below:

Good news!!! If there are any of you who need help in excel tutorials, I will be happy to arrange it $[\ldots]$ (DBP 41).

The catchy exhortative phrase "Good news!!!" extends a lifeline to students in dire straits with Excel. The lecturer presents herself as a cheerful, good-hearted lady who comes at poignant moments to rescue academically challenged students. Informal language, therefore, helps to breach social distance between parties in a perceivably asymmetrical relation of power.

\section{Discussion}

Feenberg $(1999,2002)$ argues that technological artifacts are not exclusively the result of pure engineering and design processes but are also products of conflicting views of the world. Feenberg proposes that the application of a particular technology requires understanding of its specific history and consideration of the local interpretations that users assign to it. For some academics, SNS not only became pedagogical tools for transmitting on-demand assistance to students experiencing learning difficulties but morphed into instruments for effecting social control. For example, in South African contexts where the private English speaking high school system inculcates teachers as cult figures to be addressed by decent titles, their directives are often heeded to by students. This is often extended to university online learning environments like Facebook consultations that become spaces for the territorialisation of instructor's control as students unquestionably comply with the directives irrespective of their substance.

The duality between private (personal) and professional use of Facebook potentially influenced the results in two ways. Students often considered Facebook as a space for social networking and

\footnotetext{
${ }^{5}$ Emoticons are icon-like features meant to show the feeling and mood of online participants. The emoticon: ;) was supposed to be :-) or :-) to express excitement.
} 
entertainment and not necessarily an academic engagement space. Student satiric critique on the IT department's requirement for them to join the Facebook Departmental group can be attributed to the confusion and uncertainty that accompanied their engagement with academics in a perceivably social space. Student fear of loss of control and possibility of administrative surveillance could have sparked these criticisms. On the other hand, the perceived 'anonymity' granted by Facebook communication potentially insulated some shy students from intimidating identity signifiers (facial expressions, gaze, pitch of voice) of academics often inherent in face-to-face interactions (Kiesler, Siegel, \& McGuire, 1984; Short, Williams, \& Christie, 1976). This to some degree rendered them some leverage to contest power and challenge academics in newly founded spaces.

This peculiarity (separating social from professional conduct) is not necessarily unique to students alone, but academics as well. For example, interpersonal engagement among researchers [even in the same discipline] is reportedly lacking in the university thus projecting an academy that incentivizes a near-monastic focus on one's own projects (Carpenter \& Drezner, 2010) and implicitly discourages connectivity and collective engagement. This is evidenced by many academics' remarkable faith in traditional learning management systems like Blackboard, which are inherently closed systems that emphasize controlled transmission of educator generated content, course-dependent engagement, and insulate students from outside networks. Such an inwardlooking approach is compounded by dystopian views on academic use of social networking sites, namely the risk of offending senior scholars, disclosing political partisanship, and a perception of devoting much time to non-academic engagements to the detriment of scholarly commitments (Hurt \& Yin, 2006).

When their identities are conceivably 'hidden,' students had more leverage and control over the medium of communication and communication itself. Judging from student appropriation of authoritative language and their occasional reprimand of academics, it might be envisaged that such behaviors are replicable in other computer mediated communication channels like discussion boards and chat rooms in Learning Management Systems. That said, there are caveats on the extent of use of this power. For example, although some students used Facebook to voice their complaints and disgruntlement with some Faculty's administrative practices, incidences of lecturer's use of authoritative language were higher. Therefore, she retained profound academic authority even on Facebook, suggesting the reproduction on Facebook of the power built in offline contexts.

The challenge for IT education is that, although IT educators' interest in appropriating SNS for pedagogical purposes is growing, many of them have not precisely located and conceptualised innovative Facebook usage that improves student information searching, processing, and management, reinforces task-oriented behavior, and improves IT research. Yet Facebook's capacity to foster high-yielding academic research for IS and IT educators cannot be underestimated. For example, Rosenbloom (2007) illuminates how Facebook is becoming a "petri dish for the social sciences" academics' conduct of research by allowing them to examine people's networks, information and data sets in ways few databases do. Rosenbloom further reports University of Colorado's use of Facebook profiles to explore the diffusion of information on sensitive public issues (Virginia Tech shootings). Harvard University and the University of California at Los Angeles researchers monitored Facebook profiles of a class at an anonymous college to understand how student tastes and habits foster formation of social relationships and social capital (Rosenbloom, 2007). The aforementioned researches are located and fit well in IT topics of network analysis, information diffusion and data base management respectively. As Carpenter \& Drezner (2010, p. 260) observe: "Given the clustering and self-identification of specific communities through platforms like Facebook, [...], one could imagine a variety of means by which such platforms would facilitate targeted research of specific communities." In relation to IT education, many self- 
contained Facebook groups with an IT or information systems thrust like Anti-Spyware groups, Open Source Software groups, or Mobile Technology groups can be formed and engage researchers and/or students. Organically generated information and/or knowledge emerging from these groups can be researched to engender learning analytics on IT.

\section{Directive Language}

Student appropriation of directive language, like imperatives and authoritative discourses, in SNS interaction demonstrates that computer-mediated communication is liberating to the extent that interactants in a hierarchical relationship may be equally empowered to use statements that impose obligations and requirements on one another. The absence of body language (like facial expressions, gaze, pitch of voice, body posture), non-verbal communication, and other para-verbal cues characteristic face-to-face communication in SNS necessitates interactants to maximise interaction by using linguistic expressions, signs, and iconic features of this Web environment. More importantly, the absence of these offline features liberates perceivably subservient parties to articulate their thoughts, to voice their concerns, and to contest traditional centres of power. This unfolds through their use of imperatives, directives, and declarative language that impose assumptions about power (like question marks, exclamation marks). Interactional power, therefore, is not an exclusively private resource in the hands of the oligarchy (lecturers) but rather a transactional force strategically appropriated and redirected by all interactants to get educational intentions transmitted and exchanged. In Philosophical-Political Profiles, Habermas (1983) cites Arendt (1976) who notes that:

Since the purposively rational agent, who is exclusively interested in the success of his action, has to dispose of the means by which he can coerce a subject capable of decision (whether by threat of sanctions, by persuasion, or by skilful manipulation of alternatives for action), "power means every chance in a social relationship to assert one's will even against opposition." (Arendt, 1976, cited in Habermas, 1983, p. 171)

Both the lecturer and students are presented with the same opportunity to assert their influence and control on one another. Student statements like "make it a point" directed at the lecturer denote their attempts to territorialise social power while the lecturer's response "you must learn to ask politely otherwise you will not get" resonates with the open attempt by the expert to reclaim lost ground in a contentious conversation. The lecturer's reprimand demonstrates her conscious psychological motive to use the communicative event (or chance) to resist the student assertion of his will on her and in the process circumscribe his power.

Exercise of power on SNS has implications for organisational change and organisational development in IT education. Mindful of SNS as a contested power zone, IT educators can appropriate Facebook as a prototype of an academic-oriented enterprise resources planning (ERP) platform, that is, an integrated information systems for communicating change, managing business (or academic) processes, and servicing diverse departments in university. From an academic perspective, the ERP can address diverse lecturer-student learning relations from IT group tasks, individual self-assessments like short IT quizzes for testing general IT knowledge to handling new student recruitments. The student relations with IT faculty component of ERP can include admissions, supply and management of course registration forms, addressing general IT course queries and complaints, managing part time campus recruitments for IT students, and organisation of university faculty events.

From an institution-wide perspective, organisational change can encapsulate shifts in the delivery mode and engagement of IT students through the innovative use of Facebook. As Beckenham (2008) suggests, the rapid uptake of social networking sites presents yet another new set of challenges for the education sector and a particular need to rethink established ways of engaging with 
students and their communities. Pedagogical innovation on Facebook could foreground critical engagement with IT concepts, issues, and processes. IT educators can therefore, exploit multimodality (text, images, videos, graphics) and multi functionality of Facebook to support meaningful experiential learning through IT content-based videos, foster cooperative group engagements on current IT debates through Facebook groups, and nurture reflective and critical-peer learning through adopting Facebook as a reflective blog. This is critical to effective learning because research has proven that students are intrinsically motivated to learn due to the meaningful nature of the learning environment and activities (Kearsley \& Shneiderman, 1999).

As Wodak \& Ludwig (1999) suggest, discourse "always involves power and ideologies. No interaction exists where power relations do not prevail and where values and norms do not have a relevant role" (p. 12). Although the interactions are rooted in an informal space (Facebook) that empowers the student to subvert social hierarchy, this informality does not completely downplay the authoritative status of the lecturer in this case. The interaction mentioned above highlights the complexity of academic relations that are fostered by fluid identities as personas traverse from offline to online. This raises questions regarding whether authority completely disappears online or merely takes another form. My view that it is 'softened' allowing subjects who may dread to participate in it in face-to-face relations to be active agents in its articulation and negotiation online.

\section{Use of Irony}

The fragmentation and diffusion of centres of power in SNS interaction emerges as students employ cynicism to subtly contest power in interactional spaces disrupted by academics presence and participation. The malleability of SNS to different permutations of power manifests through student marshalling of irony and sarcasm to express disgruntlement with conceived administrative meddling in their private lives on online spaces. Students detested what they erroneously viewed as cyber "gerrymandering" orchestrated by academics to gain political mileage over them in their transactional spaces rather than an academic endeavour to support them in a learner friendly landscape. This ambivalence among students has some association with Selwyn's (2007) study that reports that Facebook is used by less academically successful students as a space for contesting the asymmetrical power relationships built into the institutional offline positions of student and formal school system. Selwyn further elaborates that Facebook, therefore, affords these students with the 'back-stage' opportunities to be disruptive and challenging and to become resistant "unruly agents." Disruptive uses of Facebook can also be interpreted as students' limited mastery of a new technological phenomenon due to limited ICT skills and digital literacies. As such, Beckenham (2008) propose that academics need to consider carefully whether, by engaging in academic sociality (or networking), they unintentionally exclude students who do not have the capacity or inclination to put their profiles online. IT educators could therefore, appropriate Facebook' easy functionality to explore diverse ways in which students with limited ICT literacies can be supported to effectively participate in IT education. In the Facebook environment, students can be trained in building profiles, building authentic knowledge networks, network analysis, building customised IT applications, managing and synthesis of invaluable collaboratively generated information, information retrieval, and IT supported decision making.

The above attests to the complexity of augmenting academic consultation in computer-mediated spaces, particularly when the strategic intentions of communicants are not declared clearly in advance to ensure mutually beneficial interaction. Academic resources (information, arguments, positionality, and perspectives) and educational gains that could mutually support interactants (lecturers, students, peers) are lost as hidden assumptions about power that underlie communicative acts are concealed. 
The above articulations demonstrate that, far from being a capacity or resource in one's hands, power is an emergent quality that can only take shape through the joint actions of all those who participate in a given set of social relations (Winter, 1996). Therefore, in Foucault's (1978) terms, although power is pervasive it is not overwhelming because students just like their educators have several ways of reacting to its exercise - to complain, to be indifferent, to challenge, or to comply with a given perspective. SNS is a battlefield through which different forms of psychological positioning and conflictual views of agency emerge activating different forms of power - a radical departure from the traditional notions of power as a universal force that directs and constrains actions. Dissecting Foucault's (1978) view on power, Winter (1996) observes that the traditional constructions of power as are "poor in resources" and "incapable of invention" (p. 795) as the emphasis is on the use of physical force or coercion by the power agent to carry out her intentions. Consistent with CTT's view of technology as products of ideological conflicts and requirements for its contextualised use, SNS create possibilities for articulation of potentially conflictual, multiple voices and interests between academics and students. More importantly, SNS afford student emancipation through providing broader choices to students in terms of the language to use in articulating their interests and subverting vertical relations of power between students and academics.

\section{Use of Agency}

SNS present power-brokering spaces where academics' and students' voices and positioning intersect to bring about potentially different epistemic frames and representations of the world. The use of agentive language like "we will see what we can do" and "it's all up to you" by the lecturer demonstrates how technology can be used to advance the promotional and facilitative dimensions of power. This exhortative use of language activates and catalyses interactants to assume positions of information seekers, information givers, reflective thinkers, and critical reviewers of peers and academics' work. The attempt at collaborative engagement and not only rivalry in communicative acts is the object of interaction. As Arendt suggests:

The communicatively engendered power of common convictions goes back to the fact that the parties are oriented towards agreement and not just towards their own respective success. To this end they employ language not in a "perlocutionary" way (i.e., not just to instigate the desired conduct in the other subjects), but in an "illocutionary way (i.e., to establish intersubjective relations free from violence) (Arendt, 1976, cited in Habermas, 1983, p. 173).

The illocutionary stance in a communicative event implies that satisfaction of personal motives is not the entire goal of text-mediated academic relations but rather realisation of common understanding as well. Arriving at mutual understanding may be a goal in itself that unites both parties to cooperate with one another as in Habermas' (1984) concept of ideal speech acts. Permissive language with agency implications, therefore, tacitly harnesses collaborative engagement in ways that foster student improved understanding on one hand and lecturer's satisfaction with effective responses as a knowledgeable expert. The agency afforded by SNS resonates with Barry's (2001) view on Web 2.0 technologies as disciplining technologies that rely on "permissive control" conditioning users to engage in some forms of contingent behaviours. The extent of academic empowerment is a function of the different affordances and contexts the technology provides for expression of agency in as such as it rides on agents' conceptualisations about the innovative use of technology.

\section{Performativity of Self-identities}

Male students' exhibitionist behaviour demonstrates how they publicly performed their masculine identities embellished by a sense of macho and egoism. The "performativity" of their identities 
(Bosch, 2008) unfolds through their sophistication in SNS language use to portray masculine bodies in virtual spaces as invincible representations and dazzling holy grails of sexuality. More importantly, imbuing masculine features on virtual features serves to project SNS interaction not as an exclusively academic networking practice but rather an aesthetic and representational ritual through which students develop images of their selves in public spaces where audiences marvel and envy them. This public performance of gender relations complements Peluchette \& Karl's (2008) finding that male students are significantly more likely than females to post selfpromoting and risqué pictures or comments (involving sex or alcohol) on their profile, whereas females were significantly more likely than males to post romantic or "cute" pictures and/or information. Such behaviours approximate those of users of discussion boards, which are often marked by some inappropriate behaviour like flaming, cyber wars, and posting sexually explicit messages. Consistent with CTT's view of technology as human controlled and value laden, SNS was subtly appropriated by male students to project their self-image to peers and to create buffers against administrative encroachment by academics.

The use of informal language creates an ambient academic online environment where academics and students meet to apprise one another of their academic interests and motives. Informal discourses on SNS may accommodate students who feel disorientated by unfamiliar discourses in university environments because very often "alienation is a consequence of inadequate socialization which is precipitated by social and psychological conditions which either facilitate or impair individual learning" (Otto \& Featherman, 1975, p. 702). It can be inferred that SNS use could be ideal for students striving to leverage their academic socialisation into university and inclined towards creating self-controlled knowledge communities to overcome alienation.

\section{Practical Implications for Pedagogy}

This research study demonstrates the different configurations of power and exercise of agency that emerge through social networked interaction. The reinforcement of hierarchical relations of power (as evidenced by use of imperatives and authorial claims), activation of lecturer-student and student-peer collaborative relations (through agentive and permissive language), and the reinforcement of hierarchical power at student-peer level (through gender performativity) are insightful for academics' pedagogical practice. Academics employed their academic authority to give declarative instructions, to guide student actions in task accomplishment, and to reprimand inappropriate behavior from students. Some students appropriated language to contest what they conceived as problematic administrative practices, like academics' expectations of their participation in departmental Facebook group discussions. Collectively, therefore, these social practices can be conceived as productive and disruptive usage of power. One pedagogical implication is that the exercise of disciplinary power should not be conceived by academics as an anathema to student learning and the organisation and application of instruction. Rather it can be a productive force through which teaching strategies (leading questions, demonstrations) and learning resources (guidelines, commands, background information) are relayed to support learning.

One of the critical aspects of Facebook use was the over-reliance on the lecturer for academic support on theoretical and conceptual issues and the limited student-peer interaction on these matters. This was noticeable from the proportion of queries students directed at the lecturer to those that were peer informed. Although another motivation of developing the Facebook group was to stir student-peer consultations (in addition to lecturer based consultation), the lecturer was conceived by most students as the staple source of authentic information. This resulted in the use of Facebook as 'virtual classroom' where the teacher was perceived to be a 'sage on the stage.' This somewhat replicated the transmission approaches characteristic of traditional face-to-face lectures. Therefore, instructional designers are challenged not to design SN learning environments that reinforce didactic teaching by duplicating face-to-face learning environments through migrat- 
ing content to online learning environments. Rather they need to develop customised features on SNS that allow students to collaboratively engage with peers and the extended academic community, to critically reflect on their learning practices and reduce dependence on the lecturers for academic support. The integration of Facebook wall features with reflective diaries for student personal reflection on content and microblogs for student collaborative engagement with peers would trigger academically engaging online learning environments. As Rambe (2008) suggests, at some South African universities like the University of Cape Town, blogging has been sought as a supplement to learning management systems (LMS) by innovative lecturers who strive to promote interactive learning environments where the educator's instructive role in knowledge production is diminished significantly. Therefore, it will be interesting to explore the configurations of power in blended learning environments involving the integration of a range of applications.

Although some nascent forms of peer-based networking on administration matters and technical procedural matters of IT were noticeable, peer engagements on conceptual and theoretical issues were short of depth. Social networking enabled playful learning and public articulation of different student roles, which needed to be emphasised in educational matters to bring more enriched engagements. The implication for IT education is that students need to transcend gender performativity and social networking by constructively aligning these forms of interaction with academic networking with the broader academic community (senior students and the extended academic community). While diverse uses of Facebook can be rendered, they need to be closely coupled with the academic component to build online communities of lifelong learners. As Acker \& Miller (2005) suggest, learning grows through a syncopated rhythm of interaction and argument, clarifying discussions, presentation and critique, and freezing and archiving. SNS' personal reflection spaces (inbox) and collaborative public spaces (wall and discussion board) can be seamlessly integrated with blogs and wikis to foster immersive environments that support deep forms of learning.

\section{Future Studies}

The different forms of interaction reported in this case study involved a young female IS lecturer and first year students academically interacting in an Information Systems course. Mindful of this, several permutations emerge for future research of this nature, for instance:

- Future studies could compare and contrast student online behaviour (forms of use, applications used, type of language used, and exercise of power) when several lecturers with different demographic characteristics moderate the discussions.

- Mindful of the fact that student participation on Facebook was a Departmental expectation, future studies could make comparisons of the extent, intensity, and nature of academic interaction of compulsory use and independent use by students.

- Given that Facebook constitutes an instance of an IS and this technology was applied in an IS department, there was a given sense of compatibility. Future research could examine implication for academic relations and learning of the appropriation and use of Facebook across a wide range of Faculties that may not be technology oriented.

- Access to Facebook was campus-based and involved student use of walk-in laboratories. Conscious of university students' access and ownership of mobile phones, further studies could examine the configurations of relations when lecturer-student and student-peer interactions unfold on these handhelds. 


\section{Conclusion}

Students and academics appropriated a wide range of communicative language and genres to articulate agency and heed to commands as well as contest power. These varied from authorial claims, imperatives, and modal auxiliaries to satirical language harnessed to exercise and centralise power. While some students attempted to critique academics on the implementation of administration practices and requirement to use Facebook for academic purposes, the differential applications of power between the lecturer and students meant that Facebook seemed to reproduce and reinforce asymmetrical relations of power built offline.

In light of the above, this work concludes that social network mediated interaction presents varied opportunities and constraints that differentially empower as well as constrain possibilities for democratised academic relations. While this work does not necessarily contest the view that CMC interaction presents opportunities for student liberation from the power assumptions immanent in identity descriptors characteristic of face-to-face interactions (Postmes \& Spears, 2002; Postmes, Spears, \& Lea, 1998), it contends that this view needs substantiation and qualification. In this study there were several instantiations of the reinforcement and entrenchment of hierarchical relations involving the lecturers assuming authorial claims and directive language with which many students unquestionably complied. This seems to be another variant of online interaction possibly not envisaged in the above authors' work. Notwithstanding the isolated cases of student-directed support rendered to peers, Facebook interactions were dominated by question-based consultations that were lecturer dependent. If the view that "information is power" has substance for university freshman who are unfamiliar with practices of directed learning, then academics are warned to guard against 'parachuting' face-to-face didactic teaching in online learning environments.

The use of the Facebook environment provided some insights on limitations of hierarchical academic relations which include rote learning, dependence on the lecturer for information that reinforce academic patronage, and fear of overtly critiquing academic shortcomings of faculty. However, the Facebook learning environment created an educative and aesthetic space through which identities could be contested and multiple voices represented. The variations in student response to the lecturer's commands suggest that the richness of Facebook contextual resources (textmediated, asynchronous interaction, affordances for use of hybrid language and iconic features) offered both opportunities for liberalised engagements as well as constraints in terms of realisation of self-interests.

\section{References}

Acker, S. R., \& Miller, M. D. (2005). Campus learning spaces: Investing in how students learn. Educause Centre for Applied Research, Research Bulletin 2005, (8), 1-11.

Arendt, H. (1976). On the concept of power. In J. Habermas (1983). Philosophical-political profiles. (Trans: F. G. Lawrence). London: Heinemann.

Barry, B. (2001). Political machines: Governing a technological society. London: Athlone Press.

Beckenham, A. (2008). Face off online: Pedagogy and engagement in social network sites, in Engaging Communities, Proceedings of the 31st HERDSA Annual Conference, Rotorua, 1-4 July 2008, pp. 6670.

Bosch, T. (2008). Wots ur ASLR? Adolescent girls' use of cell phones in Cape Town. Proceedings of the e/merge online conference. July 7-18. Retrieved from http://emerge2008.net/access/content/group/emerge2008/PresentationFiles/Bosch/MXit-\%20Bosch.pdf

Bosch, T. (2009). Using online social networking for teaching and learning: Facebook use at the University of Cape Town. Seminar presented at the University of Cape Town, April 16, 2009. 
Boyd, D. M., \& Ellison, N. B. (2007). Social network sites: Definition, history, and scholarship. Journal of Computer-Mediated Communication, 13(1), article 11. Retrieved July 01, 2010, from http://jcmc.indiana.edu/voll3/issue1/boyd.ellison.html

Bishop-Russell, J., Dubord, M., Hansen, E., \& Webster, K. (2006). Acknowledging a campus.com(munity): [thefacebook] and diversity college. The University of Maine. Retrieved May 13, 2010, from www.studentaffairs.com/vcs/2006entries/UniversityofMaine.ppt

Brey, P. (2008). The technological construction of social power. Social Epistemology, 22(1), 71-95.

Cain, J. (2008). Online social networking issues within academia and pharmacy education. American Journal of Pharmaceutical Education; 72(1), 1-7.

Carpenter, C., \& Drezner, D. W. (2010). International Relations 2.0: The implications of new media for an old profession. International Studies Perspectives, 11, 255-272.

Centre for Educational Technology. (2009). Projects. Retrieved March 12, 2010, from http://www.cet.uct.ac.za/projects\#MobileLearning

Chickering, A. W., \& Reisser, L. (1993). Education and identity (2nd ed.). San Francisco: Jossey-Bass.

Chigona, A., \& Chigona, W. (2008). Mix it up in the media: Media discourse analysis on a mobile instant messaging system. The Southern African Journal of Information and Communication, Issue 9, 42-57.

Cummins, J. (1997). Minority status and schooling in Canada. Anthropology and Education Quarterly, 28(3), 411-430.

Dusek, V. (2006). Philosophy of technology: An introduction. Malden, MA: Blackwell.

Ellison, N. B., Steinfield, C., \& Lampe, C. (2007). The benefits of Facebook friends: Social capital and college students' use of online social network sites. Journal of Computer Mediated Communication, 12(4), article 1. Retrieved May 3, 2010, from http://jcmc.indiana.edu/vol12/issue4/ellison.html

Fairclough, N. (1989). Language and power. New York: Longman.

Fairclough, N. L. (1995). Media discourse. London: Edward Arnold.

Feenberg, A. (1999). Questioning technology. New York: Routledge.

Feenberg, A. (2002). Transforming technology: A critical theory revisited. New York: Oxford University Press.

Feenberg, A. (2003). What is technology? Lecture for the Komaba undergraduates, June 2003. Retrieved November 17, 2009, from http://www.sfu.ca/ andrewf/books/What is_Philosophy_of Technology.pdf

Feenberg, A. (2005). Critical theory of technology: An overview. Tailoring Biotechnologies, 1(1), 47-64.

Feenberg, A., \& Barney, D. (2004). Community in the digital age: Philosophy and Practice. New York: Rowman and Littlefield Publishers.

Flynn, L. J. (2008). MySpace mind-set finally shows up at the office. New York Times. Retrieved June 15, 2009, from http://www.nytimes.com/2008/04/09/technology/techspecial/09socialprise.html? rr=3\&ref=techspecial $\underline{\text { \&oref }=\text { slogin }}$

Foucault, M. (1978). The history of sexuality (trans: R. Hurley). Penguin Books.

Foucault, M. (1981). The history of sexuality: An introduction. London: Penguin.

Foucault, M. (2003). The essential Foucault: Selections from the essential works of Foucault. In P. Rabinow \& N. Rose (Eds). New York: The New Press.

Gratham, C. (2009). Incorporating critical theory of technology into educational leadership: Examining the technical codes of the open journal system. Access to knowledge: A Course Journal, 1(2), 1-11. 
Gross, R., \& Acquisti A. (2005). Information revelation and privacy in online social networks. Workshop on Privacy in the Electronic Society (WPES 05). Retrieved June 12, 2010, from http://portal.acm.org/citation.cfm?id51102214

Habermas, J. (1983). Philosophical-political profiles (Trans: F.G. Lawrence). London: Heinemann.

Habermas, J. (1984). The theory of communicative action (Volume 1): Reason and the rationalisation of society. (Trans: T. McCarthy). London: Heinemann Educational Books.

Heidegger, M. (1977). The question concerning technology and other essays. New York: Harper and Row Publishers.

Hewitt, A., \& Forte, A. (2006). Crossing boundaries: Identity management and student/faculty relationships on the Facebook. $C S C W^{\prime} 06$, Banff, Alberta: Canada, 1-2.

Hurt, C., \& Yin, T. (2006). Blogging while untenured and other extreme sports. Washington University Law Review, 84, 1235-1255.

Kearsley, G., \& Shneiderman, B. (1999). Engagement theory: A framework for technology-based teaching and learning. Retrieved June 8, 2011, from http://home.sprynet.com/ gkearsley/engage.htm

Kiesler, S., Siegel, J., \& McGuire, T. W. (1984). Social psychological aspects of computer- mediated communication. American Psychologist, 39, 1123-1134.

Kolek, E. A., \& Saunders, D. (2008). Online disclosure: An empirical examination of undergraduate Facebook profiles. NASPA Journal, 45(1), 1-25.

Lampe, C., Ellison, N., \& Steinfield, C., (2006). A Face(book) in the crowd: Social searching vs. social browsing. Proceedings of CSCW-2006, New York: ACM Press.

Lenhart, A., \& Madden, M. (2007). Social networking websites and teens: An overview. Pew Internet and American life research. Pew Internet Project Data memo, January 3, 2007.

Lipkin D. (2006). A closer look: Facebook may mar even the best of resumes. Daily Bruin. Retrieved July 17, 2009, from http://www.dailybruin.ucla.edu/news/2006/jan/25/a-closer-look-Facebook-may-mar/

Otto, L., \& Featherman, D. (1975). Social structural and psychological antecedents of self estrangement and powerlessness. American Sociological Review, 40(6), 701-719.

Peluchette, J., \& Karl, K. (2008). Social networking profiles: An examination of student attitudes regarding use and appropriateness of content. CyberPsychology \& Behavior, 11(1), 95-97.

Postmes, T., \& Spears, R. (2002). Behaviour online: Does anonymous computer communication reduce gender inequality? Personality and Social Psychology Bulletin, 28, 1073-1083.

Postmes, T., Spears, R., \& Lea, M. (1998). Breaching or building social boundaries? SIDE-effects of Computer mediated communication. Communication Research, 25(6), 689-715.

Rambe, P. (2008). The challenges of using weblogs for learning in tertiary settings in Africa. Themed issue: Science, technology and society in Africa. Postamble, 4 (1), 64-79.

Read, B. (2006). Think before you share. The Chronicle of Higher Education, 52(20), A38-41.

Riva, G., \& Galimberti, C. (1998). Computer-mediated communication: Identity and social interaction in an electronic environment. Genetic, Social and General Psychology Monographs, 124, 434-464.

Rosenbloom, S. (2007). On Facebook, Scholars Link Up With Data. The New York Times, December 17, 2007. Retrieved July 12, from

http://shawndra.pbworks.com/f/On+Facebook, + Scholars+Link+Up+With+Data++New+York+Times. pdf

Selwyn, N. (2007). Web 2.0 applications as alternative environments for informal learning - A critical review. Paper presented at the OECD-KERIS International Expert Meeting on ICT and Educational Performance, Cheju Island, South Korea. Retrieved July 1, 2010, from http://citeseerx.ist.psu.edu/viewdoc/download?doi=10.1.1.117.9470\&rep=rep1\&type=pdf 
Short, J., Williams, E., \& Christie, B. (1976). The social psychology of telecommunications. New York: John Wiley \& Sons.

Simon, R. I., \& Dippo, D. (1986). On critical ethnographic work. Anthropology and Education Quarterly, $17,195-202$.

Vandeleur, S. (2010). Indigenous technology and culture in the technology curriculum: Starting the conversation. A case study. PhD Thesis, Rhodes University.

Van Dijk, T. A. (2001). Critical discourse analysis. In D. Schiffrin, D. Tannen, \& H. E. Hamilton (Eds). Handbook of discourse analysis (pp. 352-371). Blackwell Publishers.

Winter, S. L. (1996). The "power" thing. Virginia Law Review, 82(5), 721-835.

Wodak, R., \& Ludwig, C. (Ed.) (1999). Challenges in a changing world: Issues in Critical Discourse Analysis. Vienna: Passagenverlag.

\section{Biography}

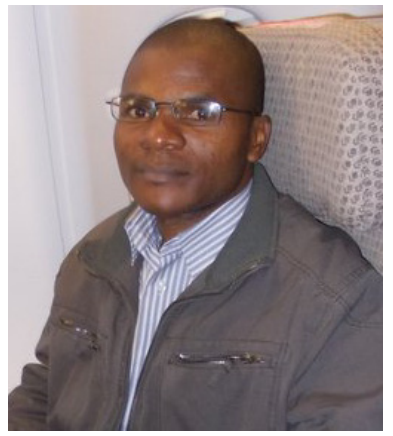

Dr. Patient Rambe holds a PhD in Educational Technology from the University of Cape Town, South Africa. His research interest is the innovative pedagogical use of social media and appropriation of emerging Web-based technologies in resource-constrained teaching and learning environments. 